Article

\title{
Investigation of Particle-Related Clogging of Sustainable Concrete Pavements
}

\author{
Aryssa Kathreen Marcaida, Tan Hung Nguyen $\$ and Jaehun Ahn* \\ Department of Civil and Environmental Engineering, Pusan National University, Busan 46241, Korea; \\ mkaaath@gmail.com (A.K.M.); nthung010189@gmail.com (T.H.N.) \\ * Correspondence: jahn@pusan.ac.kr; Tel.: +82-051-510-7627
}

Received: 11 October 2018; Accepted: 9 December 2018; Published: 19 December 2018

\begin{abstract}
Permeable pavement has been considered an effective low impact development (LID) strategy in attempts to mitigate the environmental impacts of natural surface depletion brought about by urbanization. A concern associated with the pavement's hydraulic performance is its sensitivity to clogging. This study aims to investigate the permeability reduction due to particle-related clogging of pervious concrete (PC), a type of sustainable pavement surface. Permeability tests revealed that the flow within PC samples shows turbulence, and a nonlinear relationship between discharge velocity and hydraulic gradient is necessary to measure the permeability coefficient. Permeability loss due to particle-clogging is influenced by the size of both PC aggregates and clogging particles. Clogging with graded sand particles causes more severe reduction compared to single-sized sands.
\end{abstract}

Keywords: permeability; permeable pavement; clogging behavior; constant head test; low impact development

\section{Introduction}

Over the past century, natural surfaces have been converted into impermeable finishes such as pavements, parking lots, and roofs. These changes in land use associated with urbanization have had significant effects on the hydrologic response of drainage basins, as reported by various researchers [1-5]. Consequently, the quantity and frequency of floods in streams have been magnified [5]. According to Chithra et al. [2], increases in impervious cover not only alter the urban hydrology but also degrade the aquatic ecosystem. In the event of rainfall, pollutants such as sediment, pesticides, and petroleum products, to name a few, are accumulated and rapidly transported by surface runoff to nearby water bodies. The authors note that this situation is compounded by the urban heat island (UHI) effect. This refers to the phenomenon where atmospheric and surface temperatures in urban areas are higher than in rural areas.

In spite of pervasive changes to urban hydrology, city planners and stormwater engineers have addressed the necessity of strategic planning for urban growth in order to alleviate the negative impacts of urbanization on natural resources [1,5]. Stormwater management measures commonly referred to as low impact development (LID), sustainable drainage systems (SUDs), or stormwater best management practices (BMPs) [6] have shown promise in mitigating the effects of urbanization and land development [7-9]. The underlying principle of these measures is to maintain the hydrology of an urban watershed in order to approach its natural condition before it was developed $[8,10]$. According to Coffman [10], reducing the amount of impervious surfaces of a developed site is one LID design principle that can restore the hydrologic function of a watershed.

Permeable paving is one LID measure that can be used as an alternative to conventionally impervious surfaces (such as low-traffic roadways, path walks, and car parks [8,11]), which generally catch two-thirds of rainfall in an urban watershed [12]. Unlike traditional pavement surfaces like 
concrete and asphalt, permeable pavements have voids in their structure that are specifically designed to promote infiltration and storage of stormwater through the paving layers $[6,12]$.

A number of studies have indicated the capacity of various permeable pavement materials in the attenuation of runoff rate and volume. Booth and Leavitt [13] evaluated the degree of surface runoff reduction of four permeable pavement types including Grasspave ${ }^{2 \circledast}$, Gravelpave ${ }^{2 \circledast}$, Turfstone ${ }^{\circledR}$ and UNI Eco-Stone ${ }^{\circledR}$. Based on their monitoring, they found that the permeable stalls showed virtually no surface runoff compared to the control asphalt pavement which generated a runoff nearly equal to the maximum rainfall intensity. In a laboratory test conducted by Sañudo-Fontaneda et al. [14], interlocking concrete block pavement (ICBP) models also showed a residual runoff of $0.5-10 \%$.

Runoff from street surfaces generally contains a large volume of contaminants [15]. LID pavements have been identified as being effective in filtering pollutants like suspended solids (SS) and heavy metals by trapping them within the voids of pavement layers as shown in the literature [16-19]. With the promising filtration capacity of permeable pavement comes a great concern of its susceptibility to clogging [11]. As pollutants are trapped in the voids, the hydrologic efficiency of LID pavement may be reduced. The permeability loss due to particle clogging can be very dramatic: some field tests report a $92 \%$ reduction in infiltration rates after two months of testing [20]. Some authors [21] have observed significant infiltration reductions from $290 \mathrm{~mm} / \mathrm{min}$ to $19 \mathrm{~mm} / \mathrm{min}$ after approximately two years of operation.

Many field and laboratory investigations have been made regarding the clogging dynamics of permeable pavements. The long-term performance associated with particle clogging is typically influenced by a wide range of factors and local conditions, including pavement type and design [22-24]. Laboratory assessments conducted by Andrés-Valeri et al. [22] indicated that porous concrete pavement showed less clogging potential than porous asphalt pavement due to its higher infiltration capacity and recovery from clogging. In another laboratory study [23] it was observed that particle clogging occurred on the surface for porous asphalt and on the geotextile for Hydrapave ${ }^{\circledR}$ after 12 years of stormwater simulation, whereas Permapave ${ }^{\circledR}$ showed no clogging even after 26 years. Martin et al. [24] investigated the clogging behavior of porous asphalt, with aggregate gradation considered. They found that the clogging rate can be estimated as a function of the gradation of aggregates and clogging materials.

The properties of clogging particles are also considered to have an influence on the permeability degradation of permeable pavement [25-28]. Coughlin et al. [26] evaluated the clogging effect of sand and sodium montmorillonite (clay) in pervious concrete and concluded that clay causes ten times more infiltration reduction. Regarding clogging with sand, the experiments carried out by Deo et al. [27] showed that permeability reduction was more severe with finer gradation than coarser gradation of clogging materials. Their test results along with pore size analysis revealed that there is a certain ratio of pore size to particle size that yields the highest clogging degree.

In addition to particle-related clogging, porous pavement may be clogged as a result of permanent deformation [29]. Deformation-related clogging is the reduction in void content caused by cumulative rutting from traffic loads. Pore size may also be reduced due to binder breakdown [30]. Because of the exposure to air of porous mixtures, the binder ages faster, resulting in a loss of cohesion which contributes to a reduction in pore size. The present study aims to understand the hydraulic behavior of permeable pavement, specifically that of pervious concrete. Pervious concrete is a type of permeable pavement composed of coarse aggregates only and no fines. Furthermore, the present study aims to investigate two factors that influence the clogging processes of pervious concrete: aggregate size, and clogging particle size and gradation. To accomplish this, laboratory experiments were carried out in order to evaluate the permeability characteristics of pervious concrete pavement. Permeability values were assessed in two scenarios, which were newly built and clogged condition. The scenarios considered three different aggregate sizes and four different clogging particle sizes. 


\section{Materials and Methods}

\subsection{Pervious Concrete Specimens}

Three kinds of pervious concrete (PC) specimens were used in this study. The PC mixtures were made with aggregates of the size proportions shown in Table 1, and polyurethane binder. The Elastopave ${ }^{\circledR}$ polyurethane, supplied by BASF, was composed of two components: polyol and other additives, and methylene diphenyl diisocyanate (MDI). The specimens used for testing were of a cylindrical shape, with a diameter of $100 \mathrm{~mm}$ and a height of $150 \mathrm{~mm}$.

Table 1. Pervious concrete (PC) specimen composition.

\begin{tabular}{|c|c|c|c|c|c|}
\hline \multirow{2}{*}{$\begin{array}{l}\text { Specimen } \\
\text { Designation }\end{array}$} & \multicolumn{3}{|c|}{ Percentage of Aggregates (\%) } & \multirow{2}{*}{$\begin{array}{l}\text { Nominal Max. Aggregate } \\
\text { Size (NMAS) }(\mathrm{mm})\end{array}$} & \multirow{2}{*}{$\begin{array}{c}\text { Binder } \\
\text { Content }(\%)\end{array}$} \\
\hline & $8-10 \mathrm{~mm}$ & 5-8 $\mathrm{mm}$ & $3-5 \mathrm{~mm}$ & & \\
\hline PC A & 100 & 0 & 0 & 10 & 5 \\
\hline PC B & 0 & 100 & 0 & 8 & 5 \\
\hline PC C & 0 & 0 & 100 & 5 & 5 \\
\hline
\end{tabular}

Each specimen was tested for porosity using an apparatus for the determination of theoretical maximum specific gravity and density of bituminous paving mixtures. The weights of the dry specimen and the water-filled container were measured. Then, the specimen was submerged and vacuumed while mounted on a shaking table for at least $10 \mathrm{~min}$. Using Archimedes' principle, the volume displaced by the specimen was taken as the volume of solids $\left(V_{s}\right)$. The volume of pores $\left(V_{p}\right)$ was then calculated by subtracting $V_{s}$ from the total volume $\left(V_{t}\right)$ obtained from linear measurements. The volumetric porosity was calculated by the equation

$$
p=\frac{V_{t}-V_{s}}{V_{t}} \times 100
$$

The pore size distribution of pervious concrete was analyzed using an image processing method. Slices of $25 \mathrm{~mm}$ thickness were trimmed from the top and bottom of the cylindrical specimen using a circular saw. Two cylinders were cut for each mixture, resulting in four slices and eight faces, with each slice containing two faces. The slices were washed, dried, and brushed to remove the debris from cutting. Their surfaces were carefully painted white using a rubber paint roller to improve the contrast between the pores and solids. Using a flatbed scanner, each surface was then scanned at 1200 dpi resolution. The resulting images were processed using ImageJ software for cropping, thresholding, de-noising, and analyzing pore sizes, a technique similar to that used by Deo et al. [27]. Figure 1 shows the pore size distribution obtained from image processing. The representative pore size is the diameter corresponding to the 50\% cumulative frequency [27]. The pore properties of each specimen can be found in Table 2. From the figure, it can be observed that the sizes of pores vary with aggregate size. It can be seen that the specimens with higher nominal maximum aggregate size (NMAS) had a higher proportion of large pores, whereas the specimens with lower NMAS had a relatively large percentage of small pores. This agrees with the findings of other studies related to image analysis of pore structure of porous materials [27,31]. 


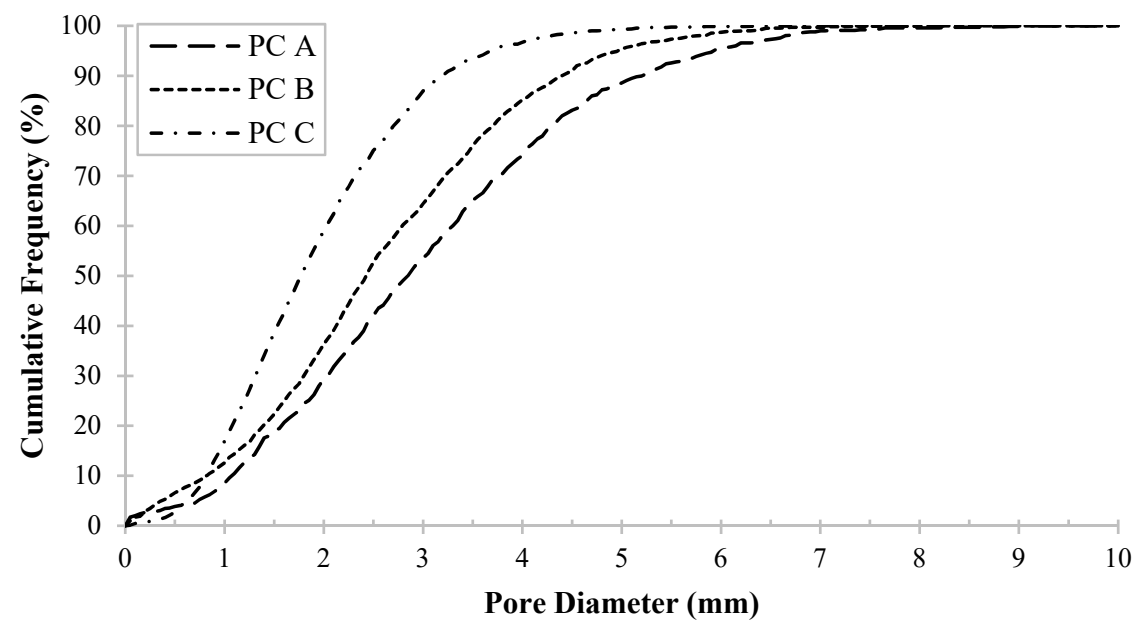

Figure 1. Pore size distribution curve of PC specimens.

Table 2. Pore properties of PC specimens.

\begin{tabular}{cccc}
\hline Specimen Designation & NMAS $(\mathbf{m m})$ & Porosity $\mathbf{( \% )}$ & Representative Pore Size $(\mathbf{m m})$ \\
\hline PC A & 10 & 30.7 & 2.847 \\
PC B & 8 & 31.0 & 2.425 \\
PC C & 5 & 34.3 & 1.768 \\
\hline
\end{tabular}

\subsection{Clogging Particles (CP)}

To simulate the clogging effects of road dust particles, dry silica sand was used to permeate the pervious concrete specimens. Four gradations of silica sand were adopted in this study: three single-sized fines ((a) CP 1-0.6-0.85 mm, (b) CP 2-0.425-0.6 mm, and (c) CP 3-0.25-0.425 mm) and one graded fine (CP 4) which represented the size distribution of road dust in Seoul, Korea [32]. The gradation of fine particles used to simulate clogging is shown in Figure 2. Gradation parameters such as the uniformity coefficient $\left(\mathrm{C}_{\mathrm{u}}\right)$ and gradation coefficient $\left(\mathrm{C}_{\mathrm{c}}\right)$ are indicated in Table 3 . The clogging particle sizes and gradation were chosen in an attempt to evaluate the critical size of uniform sand trapped in each specimen, and to investigate the effect of particle gradation on clogging.

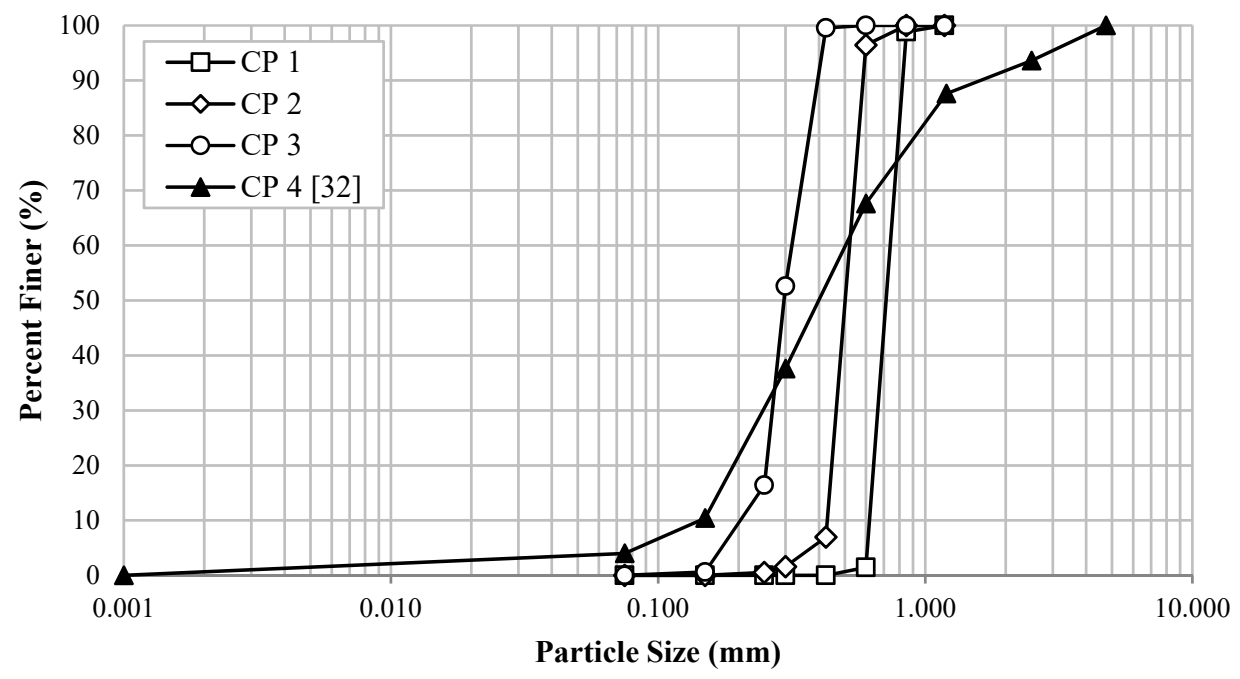

Figure 2. Particle size distribution curves of clogging particles (CPs). 
Table 3. Gradation properties of clogging particles.

\begin{tabular}{ccccc}
\hline Clogging Particle & CP 1 & CP 2 & CP 3 & CP 4 \\
\hline $\mathrm{D}_{10}(\mathrm{~mm})$ & 0.64 & 0.44 & 0.23 & 0.15 \\
$\mathrm{D}_{30}(\mathrm{~mm})$ & 0.69 & 0.48 & 0.27 & 0.25 \\
$\mathrm{D}_{60}(\mathrm{~mm})$ & 0.74 & 0.52 & 0.31 & 0.5 \\
$\mathrm{D}_{50}(\mathrm{~mm})$ & 0.7 & 0.5 & 0.3 & 0.4 \\
$\mathrm{C}_{\mathrm{u}}$ & 1.16 & 1.18 & 1.35 & 3.33 \\
$\mathrm{C}_{\mathrm{c}}$ & 1.01 & 1.01 & 1.02 & 0.83 \\
\hline
\end{tabular}

\subsection{Measurement of Permeability}

The coefficient of permeability $(k)$ is a parameter that was used to characterize the hydraulic behavior of pervious concrete in this study. Constant head permeability tests were conducted as these are more applicable to highly porous materials. A schematic diagram of the laboratory equipment used to measure $k$ is illustrated in Figure 3. Each specimen was prepared by wrapping it with layers of thin rubber and then locking it tightly in a metal casing to ensure that water flowed along the longitudinal direction of the sample. This was very important to preventing the short-cutting of flow through the side of the specimen as this situation greatly affects measurement. The specimen was then assembled over the tail frame and under the constant head frame. The constant head frame kept the water level above the sample $\left(h_{1}\right)$ maintained and an adjustable buffer tank connected to the tail frame controlled the water level for permeability evaluation $\left(h_{2}\right)$. The buffer tank was seated on a platform that could be moved at different heights using a hand wheel screw jack.

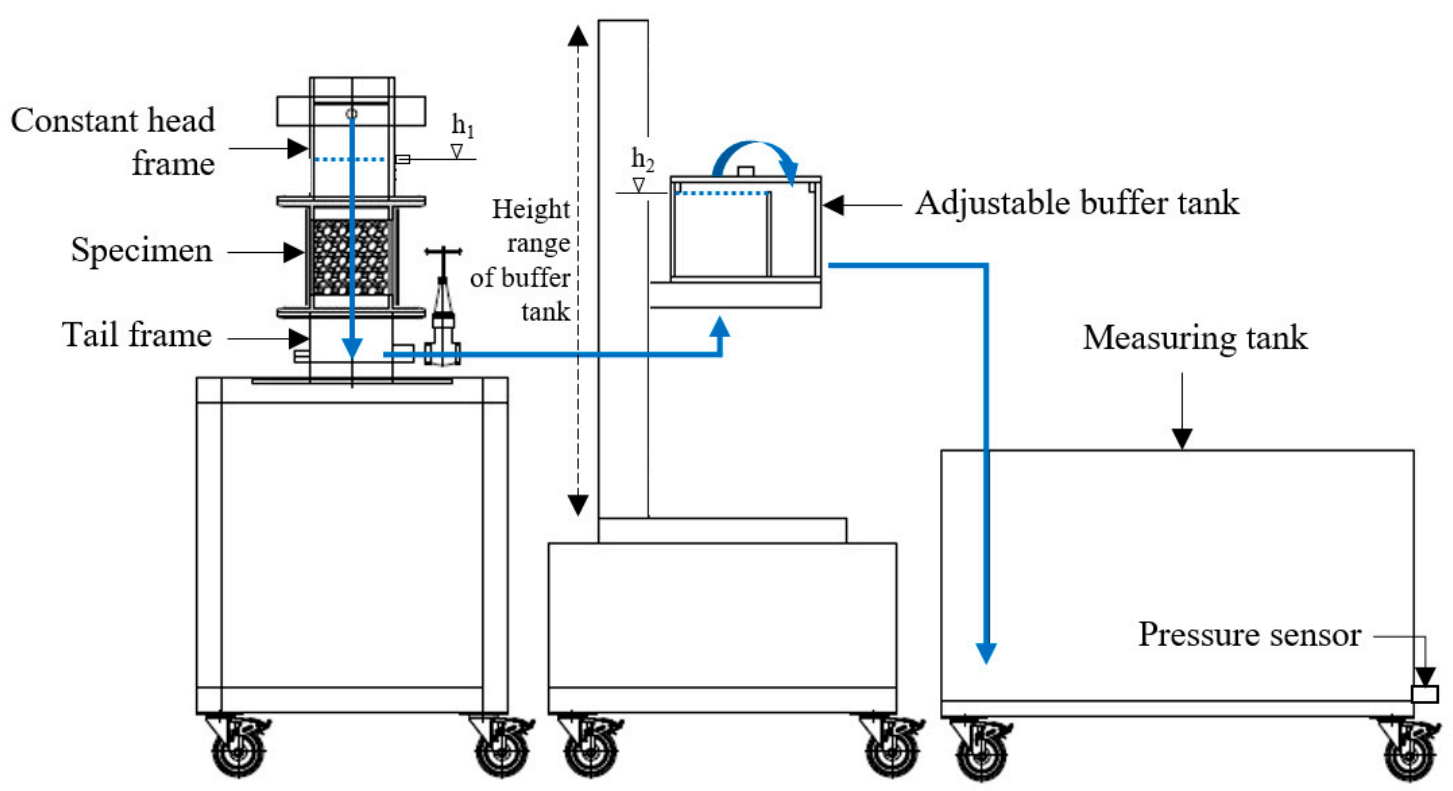

Figure 3. Constant head permeability test diagram.

During the test, water was supplied to the head frame via a flowmeter and was allowed to move through the specimen, then to the tail frame, then to the buffer tank, and finally to the measuring tank. The amount of water discharged through the sample was collected and measured while maintaining constant upper $\left(\mathrm{h}_{1}\right)$ and lower $\left(\mathrm{h}_{2}\right)$ water levels. The measuring tank was equipped with a pressure sensor that detected water level changes as water was being collected.

In the evaluation of the permeability coefficient $(k)$ of the pavement specimens used in this study, Darcy's law was not used as it is only applicable to soils which have a laminar flow condition. 
According to Darcy's law, the discharge velocity $(v)$ is directly proportional to the hydraulic gradient (i), which is given by the equation

$$
v=k i
$$

A nonlinear equation was adopted in permeability calculations as it has been observed by some authors [29-32] to produce an excellent fit when used to evaluate the permeability characteristics of highly pervious coarse-grained materials. The relationship in this equation is expressed as

$$
v=k i^{n}
$$

Authors have suggested that in a constant head permeability test, the nonlinear relationship can be obtained by measuring the discharge velocity at several different hydraulic gradients. The variable $n$ is considered to be an experimental index of flow type which is equal to 1 for laminar flow, and 0.5 for turbulent flow. The value of $k$ is equal to the value $v$ when $i=1.0[33,34]$.

\subsection{Experimental Program}

In this study, the permeability assessment was divided into two parts. The first part was the evaluation of the original permeability of the pervious samples. The second part was the monitoring of changes in the permeability characteristics of the test specimens due to particle-related clogging. After measuring the initial permeability, clogging simulations were performed. Approximately $2.5 \mathrm{~g}$ of clogging particles was sprinkled on the surface of each specimen while in the permeameter. After the addition of $\mathrm{CP}$, the permeability was measured. Sand was progressively added in $2.5 \mathrm{~g}$ increments, and then the permeability measured, until one of three conditions was met: (a) a sand cake layer was formed on the surface; (b) there was no change in the permeability coefficient; or (c) the permeability coefficient approached zero. At the end of each permeability assessment, the specimen was removed from the equipment and then de-clogged by washing with tap water using a garden hose. Efforts were made to remove all of the sand that was trapped. This was done by shaking and rotating the specimen, while it was subjected to pressure washing, for at least $30 \mathrm{~min}$. After de-clogging, the permeability was measured to verify that the original permeability had been retained. The same specimen was used for clogging evaluations using the four gradations of $\mathrm{CP}$. That is, for one pervious concrete specimen, a permeability with simulated clogging experiment was conducted four times. A total of 12 experiments were conducted with different combinations of PC specimens and CPs, as is indicated in Table 4.

Table 4. Experimental program.

\begin{tabular}{ccc}
\hline Experimental Code & Pervious Concrete Specimen & Clogging Particle \\
\hline A1 & PC A & CP 1 \\
A2 & PC A & CP 2 \\
A3 & PC A & CP 3 \\
A4 & PC A & CP 4 \\
B1 & PC B $~$ & CP 1 \\
B2 & PC B & CP 2 \\
B3 & PC B & CP 3 \\
B4 & PC B & CP 4 \\
C1 & PC C & CP 1 \\
C2 & PC C & CP 2 \\
C3 & PC C & CP 3 \\
C4 & PC C & CP 4 \\
\hline
\end{tabular}

\section{Results}

The initial permeability $\left(k_{\mathrm{o}}\right)$ of the new PC specimen was determined using the constant head concept as described in the previous section. For all specimens, the discharge velocity was measured at four different hydraulic gradients to verify the flow condition mentioned in the previous section. 
Figure 4 shows the results of the initial permeability tests conducted for A1, B1, and C1. With regard to the plot, it can be seen that the assumption of non-laminar flow in pervious concrete does hold true, since the values of $v$ and $i$ reflect a nonlinear relationship. A regression analysis was performed on these data and revealed a good fit with the modified Darcy's law equation (Equation (3)). Curve fitting parameters $k$ and $n$ were obtained, and the results are presented in Table 5. The values of $n$ appear to be less than 1.0, which indicates signs of turbulence. This is in good agreement with the results of several studies [33-36]. Furthermore, based on the initial permeability values measured, it can be concluded that particle gradation affects the infiltration ability of PC specimens. In this study, the specimen with the largest nominal maximum aggregate size had the fastest discharge velocity for all head differences, whereas the specimen with the smallest NMAS had the slowest discharge velocity. It can be seen that an increase in aggregate size corresponded to an increase in the permeability coefficient. This can be attributed to the pore structure of the material since pervious concrete specimens have pore sizes that are proportional to their aggregate sizes. As presented in Table 2, larger aggregate sizes yielded larger representative pore sizes.

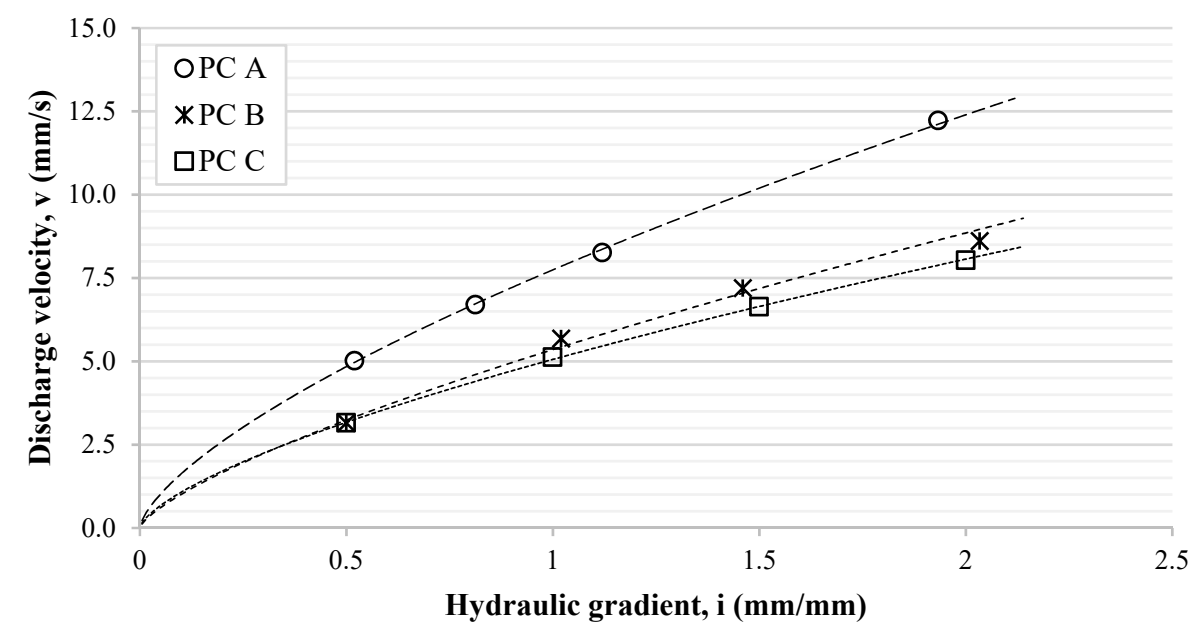

Figure 4. Plot for determining experimental variables $k$ and $n$.

Table 5. Regression analysis results.

\begin{tabular}{cccc}
\hline Specimen Designation & $\begin{array}{c}\text { Initial Permeability, } \\
\boldsymbol{k}_{\boldsymbol{o}}(\mathbf{m m} / \mathbf{s})\end{array}$ & $\begin{array}{c}\text { Experimental } \\
\text { Variable, } \boldsymbol{n}\end{array}$ & $\begin{array}{c}\text { Coefficient of } \\
\text { Determination, } \boldsymbol{R}^{\mathbf{2}}\end{array}$ \\
\hline PC A & 7.74 & 0.6786 & 0.9992 \\
PC B & 5.35 & 0.7259 & 0.9917 \\
PC C & 5.06 & 0.6737 & 0.9996 \\
\hline
\end{tabular}

The reduced permeability was monitored for the entire duration of the clogging simulations. Permeability measurements were carried out with every incremental addition of clogging particles for different PC mixtures. The normalized permeability after each cycle was calculated using Equation (4), where $k_{c}$ is the measured permeability for the current clogging cycle and $k_{o}$ is the initial permeability:

$$
\text { Normalized permeability }=\frac{k_{c}}{k_{o}}
$$

Following the measurement of reduced permeability due to particle-clogging, the specimens were de-clogged by pressure washing in an attempt to eliminate the trapped sand. The permeability at $i=1.0$ was measured to establish the initial permeability for the subsequent clogging experiment. As shown in Figure 5, the permeability was restored to its original value. The average values of $k$ for four test cases per specimen are summarized in Table 6. 


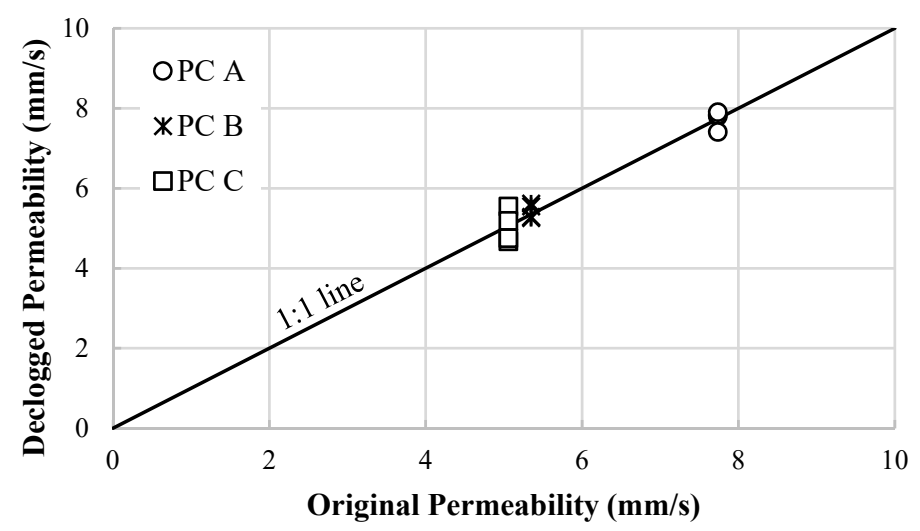

Figure 5. Relationship between initial permeability and de-clogged permeability $(i=1.0)$.

Table 6. Average initial permeability values.

\begin{tabular}{cc}
\hline Specimen Designation & Average Initial Permeability $(\mathbf{m m} / \mathbf{s})$ \\
\hline PC A & 7.73 \\
PC B & 5.43 \\
PC C & 5.03 \\
\hline
\end{tabular}

Figure 6 shows the permeability reduction in PC specimens A, B, and C after different clogging cases. Three single-sized clogging particles (CP 1, CP 2, and CP 3 ) having mean diameters $\left(\mathrm{D}_{50}\right)$ of 0.7 , 0.5 , and $0.3 \mathrm{~mm}$, respectively, were used to investigate which road dust size is critical to a particular gradation of pervious concrete pavement. The critical particle size was assessed depending on the degree of permeability loss measured before the terminal stage was reached (i.e., the stage at which one of the conditions discussed in the previous section was met). Furthermore, one non-uniformly graded sand (CP 4) having mean diameter of $0.4 \mathrm{~mm}$ was used to assess the effect of clogging particle gradation to clogging behavior.

From Figure $6 a$, it can be observed that the permeability of sample A was reduced to a maximum of $34 \%$, which was caused by CP 2 . Clogging particles CP 1 and CP 3 both reduced the permeability by only $14 \%$, with $\mathrm{CP} 1$ having a higher clogging rate than $\mathrm{CP} 3$. For this specimen, A1 was observed to have a relatively large clogging particle size compared to pore size, which inhibited more particles from entering through the voids. A3 was observed to have a relatively small particle size compared to pore size, which resulted in the passage of most particles through the end of the specimen. When considering the slope of the curves for $\mathrm{A} 1, \mathrm{~A} 2$, and $\mathrm{A} 3$, it can be seen that the slope is at a maximum for A1 until midway through the clogging simulation. This suggests that the surface pores were easily blocked by large particles but only until the addition of a total of $12.5 \mathrm{~g}$. After that, further addition of particles did not show more permeability reduction because sand could no longer penetrate the pores. A2 was found to have reached further sand addition and showed the most severe degree of clogging. This implies that $\mathrm{CP} 2$ has the highest potential of being trapped and retained in the pores, among the three CP.

From Figure $6 \mathrm{~b}$, it may be noted that B1, B2, and B3 reveal reductions in permeability of $6 \%$, $26 \%$, and $67 \%$, respectively. B1 and B2 were barely clogged due to their relatively small pore sizes, compared with the large particle sizes which resulted in unsuccessful clogging of a majority of the particles. B3 exhibited the highest clogging effect. However, the rate of clogging was so gradual that it took $60 \mathrm{~g}$ of sand to reach the terminal stage. CP 3 was found to be successfully trapped in pores, based on its consistent clogging rate. 


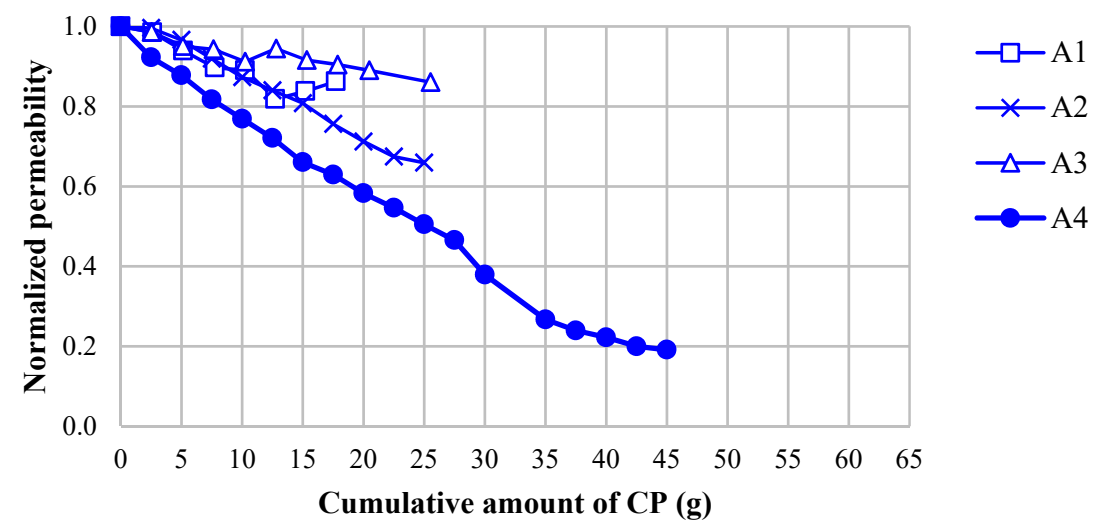

(a)

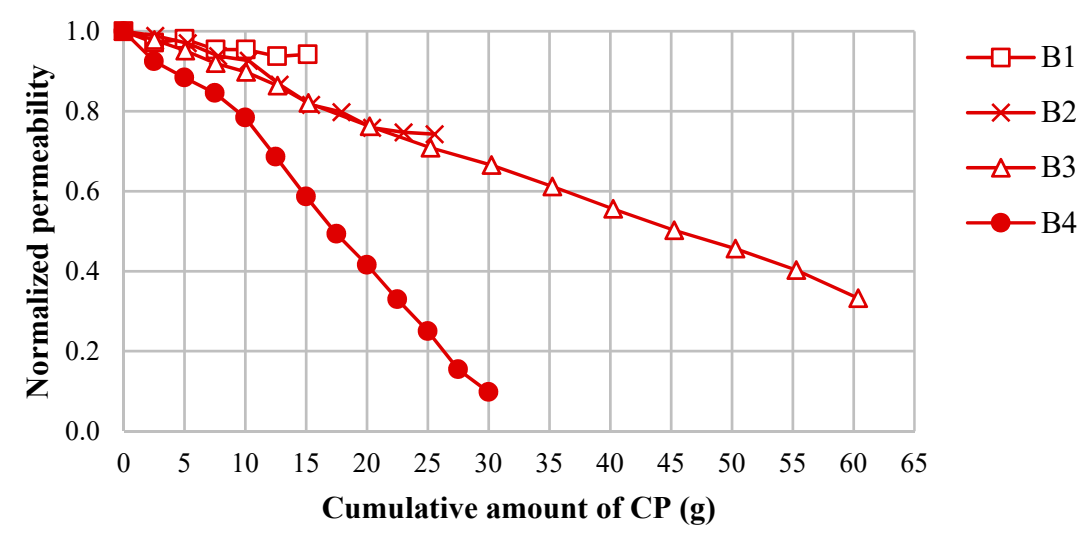

(b)

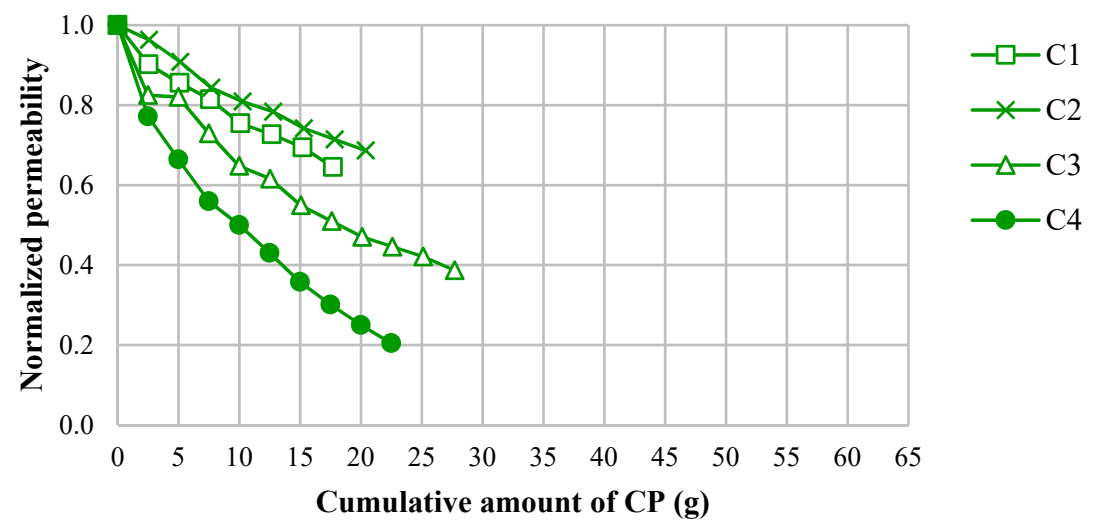

(c)

Figure 6. Reduction in permeability coefficients during particle clogging simulations: (a) PC A; (b) PC B; and (c) PC C.

From Figure $6 \mathrm{c}$, it can be concluded that the permeability of $\mathrm{C} 3$ was reduced by twice as much as for $\mathrm{C} 1$ and $\mathrm{C} 2$, which had permeability losses of $35 \%$ and $31 \%$, respectively. For specimen C, CP 1 and $\mathrm{CP} 2$ were also observed to be relatively large with regard to penetration of the pores. CP 3 was found to have a gradation that could successfully clog sample $C$, exhibiting the highest clogging rate (maximum slope) and resulting in a 61\% permeability loss. CP 3 was considered to be critical for both samples B and C, but due to the difference in NMAS and corresponding pore size, a lesser amount of sand was needed to clog sample $C$ than $B$. 
From the results of the clogging simulations, it was found that for all aggregate sizes there were clogging particle sizes that seemed too big and too small which failed to effectively reduce the pore sizes of pervious concrete. It was found that clogging particles between those sizes were successfully trapped in the pores, yielding the highest permeability losses. Among these successful clogging sizes, the smallest is considered to be the size that causes the most severe permeability reduction, because the terminal permeability of clogged pervious concrete will be governed by the permeability of the clogging material. For this reason, clogging is considered to be significantly influenced by the minimum particle size that can be trapped in (and not flushed from) the pores. Based on these observations, the effective diameters of the critical clogging particles for sample A (NMAS $=10$ ), sample B (NMAS $=8)$, and sample C (NMAS $=5)$ are $0.5,0.3$ and $0.3 \mathrm{~mm}$, respectively. It should be noted that sample A has the highest pore size and sample $C$ has the smallest pore size (see Table 2). This may imply that the critical particle size varies with NMAS as well as representative pore size of pavement material.

The degree of clogging due to non-uniform sand (CP 4) was also assessed for the three PC mixtures. CP 4 represents the gradation of actual road dust that was collected from Seoul, Korea. Based on Figure 6, permeability loss due to graded sand ranged from $80-90 \%$. This is relatively high compared to the degree of clogging caused by the single-sized sands which amounted to a maximum of $67 \%$ permeability reduction and an average of $32 \%$. Unlike the single-sized clogging particles, CP 4 contained particles of a wide range of sizes. The larger sands filled surface pores easily and the smaller sands were deposited in tinier voids, causing a much greater pore size reduction.

Based on the results of A4, B4, and C4, it can be seen that there is a decrease in the amount of particles needed to reach the terminal stage of clogging when there is a decrease in the aggregate size. This indicates that particle clogging occurs faster for pervious concrete mixtures with smaller NMAS. As mentioned in the previous section, specimens with larger aggregates have bigger pores, and require more particles to fully clog the voids. This may suggest that increasing the nominal maximum aggregate size of pervious concrete can be effective in delaying the permeability reduction caused by particle clogging.

\section{Conclusions}

In this study, constant head permeability tests were carried out to evaluate the hydraulic characteristics of pervious concrete mixtures with different nominal maximum aggregate sizes, before and after cyclic clogging simulations. From the results of the experiments reported in this study, the following conclusions can be drawn:

- Aggregate size influences the pore distribution of pervious concrete. Pervious concrete with higher NMAS contains bigger pores compared to pervious concrete with lower NMAS. Thus, an increase in NMAS results in an increase in representative pore size.

- Aside from porosity and NMAS, representative pore sizes have significant effects on the permeability of pervious concrete. The permeability was found to be $7.73,5.43$, and $5.03 \mathrm{~mm} / \mathrm{s}$ for NMAS 10, 8 , and $5 \mathrm{~mm}$, respectively. It was found that the values of permeability, NMAS, and pore size are proportionally related given similar porosities.

- For aggregates with high porosity such as the pervious concrete specimens used in this study, Darcy's law may no longer be used to determine the coefficient of permeability. A nonlinear relationship can be adopted to characterize the non-laminar flow found in highly permeable concrete mixes.

- With regard to the clogging of single-sized particles, it was observed that for certain aggregate sizes and corresponding pore sizes, some clogging particles resulted in significant pore reduction due to their size. The clogging particles that caused the highest permeability loss were found to have the smallest diameters that could allow particles to pass through the surface pores and be retained in the internal pores without being washed out. 
- A minimum permeability loss of $80 \%$ was recorded among specimens permeated with graded clogging particles, whereas for specimens subjected to single-sized sand clogging, a maximum permeability reduction of $67 \%$ was recorded. Due to the presence of particles with a wide range of sizes, the degree of clogging of non-uniform sand was more severe compared to clogging of single-sized sands.

- When the pores of pervious concrete are fully covered by clogging particles, it appears that for some test cases, the permeability at terminal stage may be limited by the infiltration capacity of the clogging materials.

Author Contributions: Conceptualization, J.A.; formal analysis, A.K.M.; funding acquisition, J.A.; investigation, A.K.M. and T.H.N.; methodology, J.A.; project administration, J.A.; resources, J.A.; supervision, J.A.; visualization, A.K.M.; writing—original draft, A.K.M.; writing—review \& editing, A.K.M. and J.A.

Funding: This research was funded by the Ministry of Land, Infrastructure, and Transport of the Korean government under the grant number 18CTAP-C132363-02 from the Technology Advancement Research Program.

Conflicts of Interest: The authors declare no conflict of interest.

\section{References}

1. Booth, D.B. Urbanization and the natural drainage system-impacts, solutions, and prognoses. Northwest Environ. J. 1991, 7, 93-118.

2. Chithra, S.V.; Nair, M.H.; Amarnath, A.; Anjana, N.S. Impacts of impervious surfaces on the environment. Int. J. Eng. Sci. Invent. 2015, 4, 27-31.

3. Hollis, G.E. The effects of urbanization on floods of different recurrence intervals. Water Resour. Res. 1975, 11, 431-435. [CrossRef]

4. Konrad, C.P.; Booth, D.B. Hydrologic Trends Associated with Urban Development for Selected Streams in the Puget Sound Basin, Western Washington; US Geological Survey: Tacoma, WA, USA, 2002.

5. Konrad, C.P. Effects of Urban Development on Floods. U.S. Geological Survey Fact Sheet 076-03; 2003. Available online: https:/ / pubs.usgs.gov/fs/fs07603/ (accessed on 11 December 2018).

6. Marchioni, M.; Becciu, G. Permeable pavement used on sustainable drainage systems (SUDs): A synthetic review of recent literature. WIT Trans. Built Environ. 2014, 139, 183-194. [CrossRef]

7. Ahiablame, L.M.; Engel, B.A.; Chaubey, I. Effectiveness of low impact development practices: Literature review and suggestions for future research. Water Air Soil Pollut. 2012, 223, 4253. [CrossRef]

8. Dietz, M. Low impact development practices: A review of current research and recommendations for future directions. Water Air Soil Pollut. 2007, 186, 351-363. [CrossRef]

9. Hunt, W.F.; Traver, R.G.; Davis, A.P.; Emerson, C.H.; Collins, K.A.; Stagge, J.H. Low impact development practices: Designing to infiltrate in urban environments. Eff. Urban. Groundwater 2010, 308-343. [CrossRef]

10. Coffman, L.S.; France, R.L. Low-impact development: An alternative stormwater management technology. In Handbook of Water Sensitive Planning and Design; CRC Press Book: Boca Raton, FL, USA, 2002; pp. 97-123.

11. Field, R.; Masters, H.; Singer, M. Status of porous pavement research. Water Res. 1982, 16, 849-858. [CrossRef]

12. Lucke, T.; Beecham, S. Field investigation of clogging in a permeable pavement system. Build. Res. Inform. 2011, 39, 603-615. [CrossRef]

13. Booth, D.; Leavitt, J. Field evaluation of permeable pavement systems for improved stormwater management. J. Am. Plan. Assoc. 1999, 65, 314-325. [CrossRef]

14. Sañudo-Fontaneda, L.A.; Rodriguez-Hernandez, J.; Vega-Zamanillo, A.; Castro-Fresno, D. Laboratory analysis of the infiltration capacity of interlocking concrete block pavements in car parks. Water Sci. Technol. 2012, 67, 675-681. [CrossRef] [PubMed]

15. Sartor, J.D.; Boyd, G.B. Water pollution aspects of street surface contaminants. Water Pollut. Control Fed. 1974, $46,458-467$.

16. Brattebo, B.; Booth, D. Long-term stormwater quantity and quality performance of permeable pavement systems. Water Res. 2003, 37, 4369-4376. [CrossRef]

17. Jiang, W.; Sha, A.; Xiao, J.; Li, Y.; Huang, Y. Experimental study on filtration effect and mechanism of pavement runoff in permeable asphalt pavement. Constr. Build. Mater. 2015, 100, 102-110. [CrossRef] 
18. Kadurupokune, N.; Jayasuriya, N. Pollutant load removal efficiency of pervious pavements: Is clogging an issue? Water Sci. Technol. 2009, 60, 1787-1794. [CrossRef]

19. Van Duin, B.; Brown, C.; Chu, A.; Marsalek, J.; Valeo, C. Characterization of long-term solids removal and clogging processes in two types of permeable pavement under cold climate conditions. In Proceedings of the 11th International Conference on Urban Drainage, Edinburgh, UK, 31 August-5 September 2008.

20. Pezzaniti, D.; Beecham, S.; Kandasamy, J. Influence of clogging on the effective life of permeable pavements. Proc. Inst. Civ. Eng. Water Manag. 2009, 162, 211-220. [CrossRef]

21. Al-Rubaei, A.M.; Viklander, M.; Blecken, G.T. Long-term hydraulic performance of stormwater infiltration systems. Urban Water J. 2015, 12, 660-671. [CrossRef]

22. Andres-Valeri, V.; Marchioni, M.; Sañudo-Fontaneda, L.; Giustozzi, F.; Becciu, G. Laboratory assessment of the infiltration capacity reduction in clogged porous mixture surfaces. Sustainability 2016, 8, 751. [CrossRef]

23. Yong, C.F.; McCarthy, D.T.; Deletic, A. Predicting physical clogging of porous and permeable pavements. J. Hydrol. 2013, 481, 48-55. [CrossRef]

24. Martin, W.D.; Putman, B.J.; Neptune, A.I. Influence of aggregate gradation on clogging characteristics of porous asphalt mixtures. J. Mater. Civ. Eng. 2014, 26. [CrossRef]

25. Chen, J.; Li, H.; Huang, X.; Wu, J. Permeability loss of open-graded friction course mixtures due to deformation-related and particle-related clogging: Understanding from a laboratory investigation. J. Mater. Civ. Eng. 2015, 27. [CrossRef]

26. Coughlin, J.P.; Campbell, C.D.; Mays, D.C. Infiltration and clogging by sand and clay in a pervious concrete pavement system. J. Hydrol. Eng. 2012, 17, 68-73. [CrossRef]

27. Deo, O.; Sumanasooriya, M.; Neithalath, N. Permeability reduction in pervious concretes due to clogging: Experiments and modeling. J. Mater. Civ. Eng. 2010, 22. [CrossRef]

28. Reddi, L.N.; Ming, X.; Hajra, M.G.; Lee, I.M. Permeability reduction of soil filters due to physical clogging. J. Geotech. Geoenviron. Eng. 2000, 126. [CrossRef]

29. Coleri, E.; Kayhanian, M.; Harvey, J.T.; Yang, K.; Boone, J.M. Clogging evaluation of open graded friction course pavements tested under rainfall and heavy vehicle simulators. J. Environ. Manag. 2013, 129, 164-172. [CrossRef]

30. Nielsen, C.B. Ravelling of Porous Pavements-Assessment of Test Section; Technical Note 48, Road Directorate; Danish Road Institute: Roskilde, Denmark, 2007.

31. Liu, R.; Liu, H.; Sha, F.; Yang, H.; Zhang, Q.; Shi, S.; Zheng, Z. Investigation of the porosity distribution, permeability, and mechanical performance of pervious concretes. Processes 2018, 6, 78. [CrossRef]

32. Seoul Metropolitan City. Standard on design, construction, and maintenance of permeable block pavements (Ver. 2.0), p.30. Available online: http:/ / www.civiltech.co.kr/xe/66700 (accessed on 18 December 2018).

33. Fwa, T.; Tan, S.; Guwe, Y. Laboratory evaluation of clogging potential of porous asphalt mixtures. Transp. Res. Board 1999, 1681, 43-49. [CrossRef]

34. Huang, B.; Mohammad, L.; Raghavendra, A.; Abadie, C. Fundamentals of permeability in asphalt mixtures. J. Assoc. Asphalt Paving Technol. 1999, 68.

35. Huang, B.; Wu, H.; Shu, X.; Burdette, E.G. Laboratory evaluation of permeability and strength of polymer-modified pervious concrete. Constr. Build. Mater. 2010, 24, 818-823. [CrossRef]

36. Tan, S.; Fwa, T.; Guwe, V. Laboratory measurements and analysis of clogging mechanism of porous asphalt mixes. J. Test. Eval. 2000, 28, 207-216. [CrossRef]

(c) 2018 by the authors. Licensee MDPI, Basel, Switzerland. This article is an open access article distributed under the terms and conditions of the Creative Commons Attribution (CC BY) license (http:/ / creativecommons.org/licenses/by/4.0/). 